\title{
Impacts of Diagnosis-Related Groups Payment on the Healthcare Providers' Behavior in China: A Cross-Sectional Study Among Physicians
}

\author{
Lingli Zhang ${ }^{1,2}$ \\ Lihua Sun iD' \\ 'College of Business Administration, \\ Shenyang Pharmaceutical University, \\ Shenyang, People's Republic of China; \\ ${ }^{2}$ Department of Pharmacy, Jinling \\ Hospital, Nanjing, People's Republic of \\ China
}

\begin{abstract}
Purpose: Currently, China is piloting diagnosis-related groups (DRG) payment system in 30 cities. The main aim of this study was to explore the respondents' impressions regarding the hospitals' policies and physicians' behavior change brought by the DRG payment system, and investigate whether and how the hospitals' policies affect the physicians' behavior.

Methods: We distributed questionnaires designed for this study to 200 physicians. Data analysis consisted of descriptive statistics, $T$-test, and network analysis.

Results: Respondents stated that the hospitals had adopted several policies in response to DRG payment and DRG payment could reduce overtreatment and improve efficiency. However, it also led to several negative effects including an increased explanation to the patients, hindering new technologies, case splitting, and cherry picking. In addition, there was no evidence that harmful effects such as refusing patients and premature discharge existed. Overall, the benefits outweighed the drawbacks of DRG. Moreover, the hospitals' policies could effectively change physician behaviors. Our results indicated that promoting the implementation of clinical pathways had the most positive impact, while limiting costs and length of stay is not recommended. Conclusion: In general, Chinese physicians who participated in the questionnaire possessed relatively positive attitudes towards the DRG payment system. Nevertheless, some of the negative impacts cannot be ignored. Meanwhile, the hospitals' policies should be implemented with adequate consideration of the impact on physicians' behavior.
\end{abstract}

Keywords: diagnosis-related groups, providers' behavior, payment system reform, China

\section{Introduction}

Diagnosis-related groups (DRG) payment has become the basis for paying hospitals in many countries. ${ }^{1}$ Essentially, DRG is a clinical case classification system where patients are classified into DRGs with similar clinical symptoms and resource consumption based on diagnosis, severity, procedure, comorbidities and other factors. Consequently, patients within the same DRG are deemed to be medically and economically similar. ${ }^{2}$ Under DRG payments, hospitals receive a prospectively fixed amount for each admission according to the patients DRG instead of the actual inpatient expenditure. ${ }^{3}$ DRG payment has led to reduced overuse of the health service because it introduces financial risk to healthcare providers. Therefore, DRGs can improve efficiency, reduce the length of stay (LOS), and control the cost of treatment. However, some studies have reported that the DRG payment system led to some unintended consequences such as decreased quality of care, ${ }^{4}$ dumping, ${ }^{5}$ upcoding, and frequent readmissions. ${ }^{1}$
Correspondence: Lihua Sun College of Business Administration, Shenyang Pharmaceutical University, No. 103 Wenhua Road, Shenyang, II00I6,

People's Republic of China

Tel +862423986553

Emailslh-3632@I63.com 
The total medical expenses in China reached 6.5 trillion yuan ( $\$ 945$ billion) in 2019 , accounting for $6.6 \%$ of the gross domestic product (GDP). ${ }^{6}$ In addition, the per capita health expenditure soared from 1807 yuan in 2011 to 4237 yuan in 2018 , which far exceeded the per capita GDP growth rates. ${ }^{7}$ A previous report indicated that more than $95 \%$ of the Chinese population are covered by the country's basic medical insurance programs. ${ }^{8}$ The rising health expenditure has brought a heavy economic burden to both the individual patient and the national medical insurance programs. The burden was largely contributed by the previous payment system where Chinese hospitals were mainly reimbursed through the fee-for-service (FFS) system. Under the FFS payment system, providers are more inclined to engage in moral hazard behavior through providing patients with unnecessary services in order to maximize their revenue. ${ }^{9}$ Therefore, the FFS is culpable for driving the growth in health expenditures. As a result, the Chinese government promulgated the Guiding Opinions on Further Deepening the Reform of Basic Medical Insurance Payment Methods in 2017, with the overarching goal of containing the soaring health expenditure growth. ${ }^{10}$ Since then, the payment system has been reformed nationwide from FFS to a mixed prospective payment system, including the DRG payment system.

In June 2019, The National Healthcare Security Administration of China issued a circular announcing that the country will launch a DRG payment pilot program in 30 cities. ${ }^{11}$ This pilot program was known as the CHSDRG (China Healthcare Security Diagnosis-related Groups). The pilot cities including Beijing, Tianjin, and Shanghai, were scheduled to start the new payment method in 2021 after a simulated run in 2020. Although a few cities such as Beijing have held local DRG pilots before, this is the first nationwide implementation of genuine DRGs pilots.

It is worth noting that the providers' behavior determines the quality, efficiency, equity, and cost of healthcare. With this in mind, many researchers in different countries have focused on the impact of the DRG payment system on providers' behavior. ${ }^{12-15}$ However, the research on the effects of the DRG payment system on providers' behavior in China is lacking. Previous DRG studies in China have paid more attention to cost control, thereby paying less attention to provider behavior. ${ }^{16}$ The few existing papers that have mentioned change of the provider's behavior under DRG in China are either theoretic works ${ }^{2,17}$ or single case analyses which were difficult to achieve a comprehensive assessment. ${ }^{3,18,19}$ Moreover, no prior report has presented the effects of the DRGs on providers' behavior from the physicians' perspectives.

The perspectives from physicians, as reform practitioners, may shed light on the changes of providers' behavior that are not captured by quantitative indicators recorded in the hospital data. The fact that the DRG payment system will be used in China for the first time means that the systematic and comprehensive study of the potential impact of DRG payment on providers' behavior is urgently needed. This study aimed at determining how the hospitals respond to the DRG payment system, the detailed behavior change in physicians' healthcare practice, and whether and how the hospitals' policy affect the physicians' behavior. Our findings will inform step-wise implementation across China on how to develop relevant policy and regulate physician behavior, thereby improving the healthcare quality, and also providing a useful reference for other low- and middleincome countries (LMICs) in the process of reforming their payment systems.

\section{Materials and Methods Study Sample}

Five sample cities were selected in the $30 \mathrm{DRG}$ payment pilot cities according to the geographical locations because of the huge economic and medical disparities between regions. The five sampled cities included Foshan in South China, Beijing in North China, Shanghai in East China, Chongqing in West China, and Wuhan in Central China. These five cities spanned five regions of China, and they covered the municipality, provincial capital city, and prefecture city in order to ensure that the samples were representative.

The sample size was calculated according to the results of the pilot study and using the G-power analysis program (version 3.1.9.7). ${ }^{20}$ We assumed an effect size of 0.5 , type I error $(\alpha)$ of 0.05 , power $(1-\beta)$ of 0.80 . The output was 102 samples. Considering that some questionnaires would be excluded, the sample size was expanded to 200 . We invited 200 physicians (40 physicians from each city) working in different hospitals to participate in this crosssectional study. To guarantee that the survey results were reliable, we excluded physicians who claimed they were not familiar with DRG. Ethical approval was obtained from the Ethics Committee of Shenyang Pharmaceutical University. 


\section{Questionnaire}

In China, medical expenditures are reimbursed to hospitals rather than the individual, and physicians received bonuses from hospitals according to the revenues they generated. The change to the DRG payment system will lead to the implementation of new policies by hospitals in response to the cost containing pressure. Subsequently, the economic pressure will be transmitted to individual departments and physicians. Therefore, we assumed that the impact of the DRG payment reform on physicians' behavior is not directly generated, but through the hospitals' policy (Figure 1). In this study, we defined both hospitals' policy and physicians' behavior as providers' behavior.

The administered questionnaire was divided into three parts based on the above-mentioned assumptions: (I) personal data; (II) hospitals' policy; and (III) physicians' behavior. Single-choice questions were used to collect the respondents' data, while multiple-choice questions surveyed the hospitals' policy to DRG payment. The questions about physician behavior change were scored using a 5-point Likert scale, with 1 representing "Strongly disagree" and 5 representing "Strongly agree". The participants expressed the intensity of agreement towards given statements which included both positive and negative impact on physicians' behavior caused by the DRG payment system. The questionnaire designed specifically for this survey is shown in the supplementary file (Appendix 1).

We developed the initial questions based on the topics that are mostly discussed under DRG payment by analyzing relevant literature and the physicians' opinion. Furthermore, the questionnaire was adapted and modified

\section{Payment method reform}

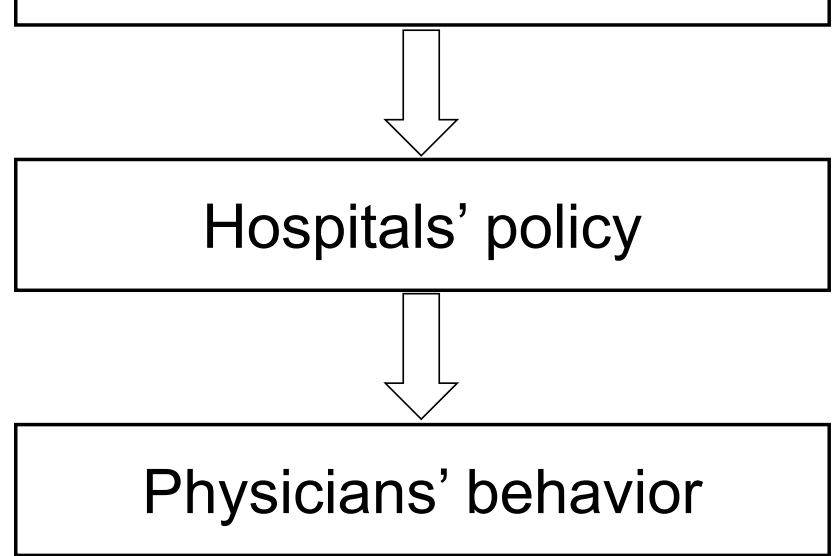

Figure I Physicians' behavioral response to payment incentives. based on the feedback obtained from our pilot test before administering it to the target survey respondents. Six experts were invited to test the content validity of the questionnaire. We calculated the content validity index (CVI) in order to quantify each item's importance, appropriateness, and clarity. Our results indicated that the values of all item-level CVI were greater than 0.8. In addition, we examined the internal consistency reliability using Cronbach $\alpha$, and the value was 0.802 . Thus, the questionnaire had a good reliability and validity. We used Questionnaire Star, a professional online questionnaire software platform, to design and create a link to the questionnaire. The questionnaires were then sent out between August 2020 and October 2020 using WeChat after explaining the goals of the survey and the anonymity claims. Notably, the questionnaire was set in a way that all survey questions must be completed before the answers could be submitted.

\section{Data Analysis}

The descriptive statistical analyses were expressed as a percentage (frequency) or as a mean and standard deviation (Mean \pm SD) on all identified variables. The implementation and non-implementation groups were divided according to whether this hospital policy was implemented in the hospital. The Likert scale was considered as a continuous scale, and each answer in the hospitals' policy category was treated as a dichotomous variable. It has been suggested that the $T$-test is the appropriate test for detecting differences in data obtained on Likert scales. ${ }^{21}$ Therefore, $T$-test was done to examine how the hospital implemented the policy could affect the physicians' behavior. A two-sided p-value of less than 0.05 was considered to be statistically significant. Moreover, we used SPSS19.0 (IBM, Armonk, NY, USA) for all statistical calculations.

The network analysis was done using Gephi (available at http://gephi.org) in order to visualize the associations between hospitals' policy and physicians' behavior. With regard to the constructed network figure, the nodes with different colors represented different events in the network. Each yellow node represented a hospitals' policy, while the blue nodes represented a physicians' behavior. In instances where the result was considered to be statistically significant according to the $T$-test, the two events were associated and hence linked by an edge. Furthermore, the larger the node, the more edges in the network were directly associated with the node, indicating that the node is very important in the network. 


\section{Results}

\section{Characteristics of the Respondents}

The questionnaire was sent to 200 physicians in five sample cities, of which 80 physicians were excluded due to lack of adequate DRG knowledge. Among the 120 physicians who completed the questionnaire, six questionnaires were excluded due to logic errors and conflicting answers. The detailed characteristics of the respondents obtained from the valid questionnaires (114) are shown in Table 1. Among the 114 respondents, $67.5 \%$ worked in Grade-A tertiary hospital, $54.4 \%$ had a master's degree, $60.5 \%$ had 6-10 years working experience, $36.0 \%$ worked in the surgery department, $30.7 \%$ worked in internal medicine, and $49.1 \%$ were attending doctors. In each sample city, 20 to 27 physicians familiar with DRG payment were included in the final analysis.

\section{Hospitals' Policy Under DRG Payment}

Figure 2 showed the hospitals' policies for DRG payment reform according to the impressions from the respondents, which were ordered by frequency. The most commonly implemented policies were "include DRG relevant indicators in the performance appraisal system of a department or physician" with a frequency of $64.9 \%$, and "summarize the operation of DRG and give regular feedback to the department or physician" also with a frequency of $64.9 \%$. The polices that followed closely were "transform the hospital information system for DRG" $(63.2 \%)$, and "promote clinical pathway implementation" (61.4\%). On the other hand, the least implemented policies were "limit hospitalization costs" $(24.6 \%)$ and "limit the length of stay" (21.1\%).

\section{Physicians' Behavior Changes Under DRG Payment}

We explored the effects of DRG payment reform on physicians' behavior during treatment, admission, and discharge of a patient. The given statements were scored according to the respondent's degree of agreement ( $1=$ strongly disagree and $5=$ strongly agree). The positive, neutral, and negative effects of DRG are listed in Tables $2-4$, respectively. Furthermore, we sorted the mean scores from the highest to the lowest.

As shown in Table 2, the mean scores of five statements about positive effects were greater than or equal to 4, which is halfway between "agree" and "strongly agree". The other nine statements were scored between 3.5 and 4, which is halfway between "neutral" and "agree" but with a bias towards "agree". The highest
Table I Characteristic of the Respondents $(n=\mid 14)$

\begin{tabular}{|c|c|c|c|}
\hline & Characteristics & $\begin{array}{c}\text { No. of } \\
\text { Respondents }\end{array}$ & Percentage \\
\hline \multirow[t]{5}{*}{ Hospital level } & Grade-A tertiary & 77 & $67.50 \%$ \\
\hline & Grade-B tertiary & 26 & $22.80 \%$ \\
\hline & Grade-C tertiary & 4 & $3.50 \%$ \\
\hline & Secondary & 6 & $5.30 \%$ \\
\hline & Primary & 1 & $0.90 \%$ \\
\hline \multirow{3}{*}{$\begin{array}{l}\text { Education } \\
\text { level }\end{array}$} & Doctor & 27 & $23.70 \%$ \\
\hline & Master & 62 & $54.40 \%$ \\
\hline & Bachelor & 25 & $21.90 \%$ \\
\hline \multirow{4}{*}{$\begin{array}{l}\text { Years in the } \\
\text { profession }\end{array}$} & I-5 years & 20 & $17.50 \%$ \\
\hline & $6-10$ years & 69 & $60.50 \%$ \\
\hline & II-20 years & 17 & $14.90 \%$ \\
\hline & $\begin{array}{l}\text { More than } 20 \\
\text { years }\end{array}$ & 8 & $7.00 \%$ \\
\hline \multirow[t]{5}{*}{ Department } & Internal medicine & 35 & $30.70 \%$ \\
\hline & Surgery & 41 & $36.00 \%$ \\
\hline & Gynecology & 15 & $13.20 \%$ \\
\hline & Paediatrics & 15 & $13.20 \%$ \\
\hline & Others & 8 & $7.00 \%$ \\
\hline \multirow[t]{5}{*}{ Job title } & Chief doctor & 13 & $11.40 \%$ \\
\hline & $\begin{array}{l}\text { Associate chief } \\
\text { doctor }\end{array}$ & 24 & $21.10 \%$ \\
\hline & Attending doctor & 56 & $49.10 \%$ \\
\hline & Resident doctor & 17 & $14.90 \%$ \\
\hline & Others & 4 & $3.50 \%$ \\
\hline \multirow[t]{5}{*}{ City } & Shanghai & 27 & $23.70 \%$ \\
\hline & Beijing & 23 & $20.20 \%$ \\
\hline & Wuhan & 23 & $20.20 \%$ \\
\hline & Foshan & 21 & $18.40 \%$ \\
\hline & Chongqing & 20 & $17.50 \%$ \\
\hline
\end{tabular}

mean score was 4.18, which was "strict control of the surgical indications", while the lowest mean score was 3.58, which was "reduce the use of Chinese patent medication or herbal injections". In general, the physicians identified a lot of positive effects brought about by the DRG payment system. For example, the overtreatment 


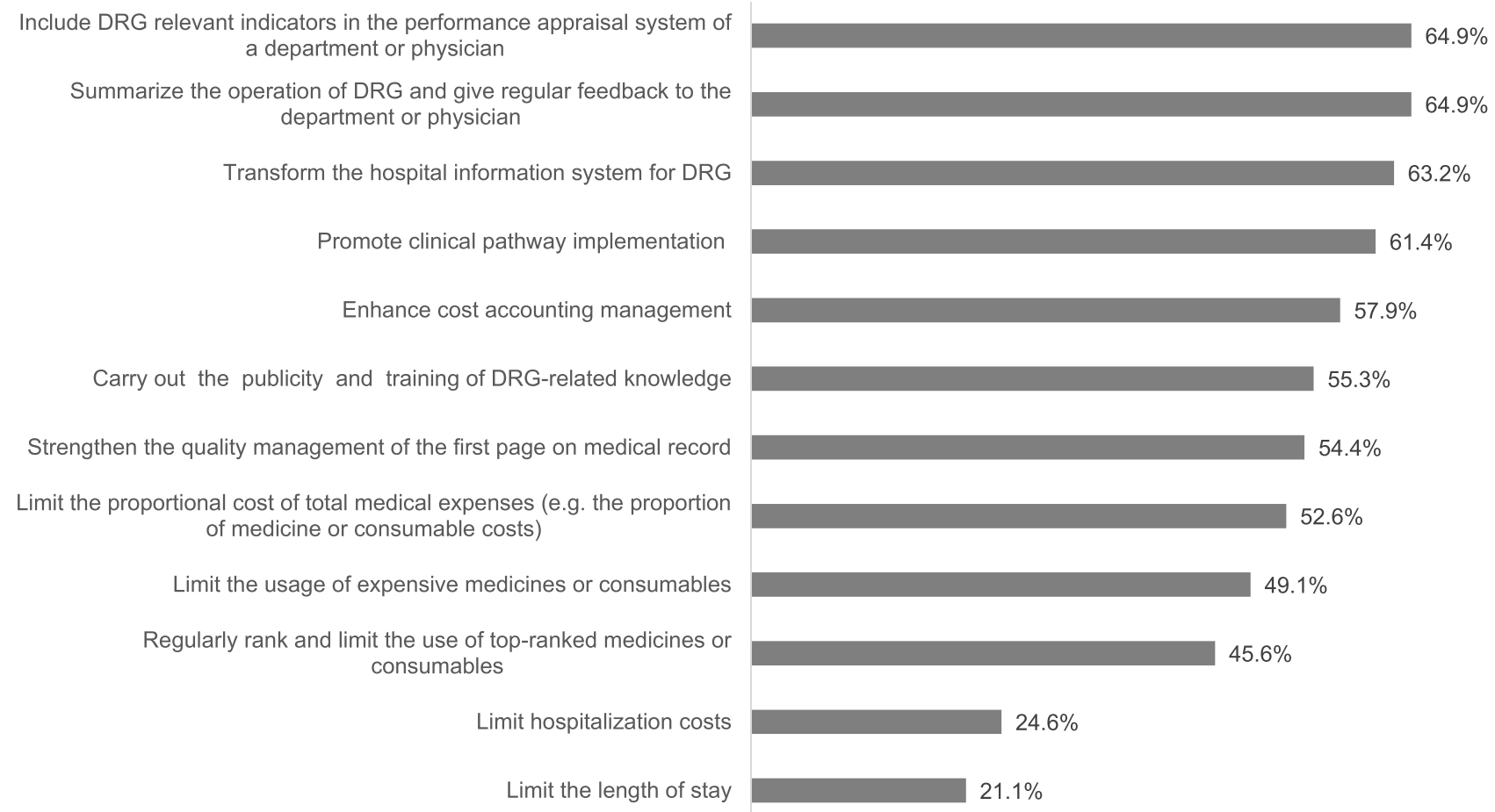

Figure 2 Frequency of hospitals' policy for DRG payment (multiple choice).

under FFS payment was reduced after the introduction of DRG due to strict control of the surgical indications, more compliance with clinical pathway, and the reduction of unnecessary services including expensive consumables, prophylactic antibiotics, and adjuvant medications. DRG payment can also improve the efficiency though reducing the waiting time and LOS, and performing more day or minimally invasive surgery. In addition, there was a decline in the intensity of care including both the number and the time of medications prescribed, as well as the examination after admission. Therefore, the DRG payment system seemed to encourage physicians to practice in a more cost-effective way in order to keep the total cost within the pre-defined price.

The results indicated that $76 \%$ of the physicians agreed or strongly agreed with more pre-admission examinations after DRG payment. With regard to the administration of drugs, more than half of the physicians agreed or strongly agreed that they replaced higher-priced originals with lowerpriced generics under DRG payment. The mean value of the agreement to "increase patient referrals" was 3.29 , which is halfway between "neutral" and "agree" (Table 3 ).

The negative effects of DRG payment reform on physicians' behavior are shown in Table 4. Our results indicated that only one statement (increase explanation to the patients) was scored above 4, while seven statements were scored between 3 and 4 . The participants agreed that some negative effects existed including more explanation to the patients, reducing expensive new sophisticated technology, case splitting, selecting the more profitable cases, and accepting more patients without medical insurance or nonlocal. Moreover, "cost shift to outpatient", "increase volumes of admissions" and "upcode" were slightly over the balance point of 3 , which means that their attitude to the three negative effects were nearly neutral. "Increase use of out-of-pocket medications", "refuse to admit critically ill patients", "premature discharges", and "deny care to cases with over the ceiling prices" all had a mean score below 3. More participants disagreed (selected either disagree or strongly disagree) about the above four statements than those that agreed (selected either agree or strongly agree). Overall, the negative effect mean score (3.20) was lower than that on positive effect (3.92), which indicated that the benefit of the DRG payment system outweighed its harm.

\section{Relationship Between Hospitals' Policy and Physicians' Behavior}

The scores indicating the level of agreement with the statements about the physicians' behavior were compared 
Table 2 Positive Effects of DRG Payment Reform on Physicians' Behavior

\begin{tabular}{|c|c|c|c|c|c|c|c|}
\hline & $\begin{array}{l}\text { Strongly } \\
\text { Disagree }\end{array}$ & Disagree & Neutral & Agree & $\begin{array}{l}\text { Strongly } \\
\text { Agree }\end{array}$ & Mean & SD \\
\hline Strict control of the surgical indications & $1.8 \%$ & $2.6 \%$ & $5.3 \%$ & $57.0 \%$ & $33.3 \%$ & 4.18 & 0.80 \\
\hline Optimize treatment process and reduce waiting time & $0.0 \%$ & $3.5 \%$ & $14.0 \%$ & $49.1 \%$ & $33.3 \%$ & 4.12 & 0.78 \\
\hline More compliance with clinical pathway & $0.0 \%$ & $0.0 \%$ & $7.9 \%$ & $76.3 \%$ & $15.8 \%$ & 4.08 & 0.48 \\
\hline Reduce the use of expensive consumables & $0.9 \%$ & $7.0 \%$ & $14.9 \%$ & $40.4 \%$ & $36.8 \%$ & 4.05 & 0.94 \\
\hline Reduce the use of prophylactic antibiotics & $0.9 \%$ & $4.4 \%$ & $20.2 \%$ & $43.0 \%$ & $31.6 \%$ & 4.00 & 0.88 \\
\hline Increase the performance of minimally invasive surgery & $1.8 \%$ & $6.1 \%$ & $16.7 \%$ & $43.9 \%$ & $31.6 \%$ & 3.97 & 0.95 \\
\hline Increase the performance of day surgery & $0.9 \%$ & $2.6 \%$ & $26.3 \%$ & $42.1 \%$ & $28.1 \%$ & 3.94 & 0.86 \\
\hline Increase the use of essential medications & $0.0 \%$ & $7.0 \%$ & $23.7 \%$ & $38.6 \%$ & $30.7 \%$ & 3.93 & 0.91 \\
\hline Reduce the use of adjuvant medications & $2.6 \%$ & $5.3 \%$ & $17.5 \%$ & $48.2 \%$ & $26.3 \%$ & 3.90 & 0.94 \\
\hline Reduce the number of medications prescribed & $0.0 \%$ & $10.5 \%$ & $20.2 \%$ & $43.0 \%$ & $26.3 \%$ & 3.85 & 0.93 \\
\hline Reduce the time of medications prescribed & $0.0 \%$ & $11.4 \%$ & $21.9 \%$ & $42.1 \%$ & $24.6 \%$ & 3.80 & 0.94 \\
\hline Reduce the examination after admission & $1.8 \%$ & $12.3 \%$ & $19.3 \%$ & $44.7 \%$ & $21.9 \%$ & 3.73 & 1.00 \\
\hline Shorten the length of stay & $2.6 \%$ & $6.1 \%$ & $24.6 \%$ & $49.1 \%$ & $17.5 \%$ & 3.73 & 0.92 \\
\hline $\begin{array}{l}\text { Reduce the use of Chinese patent medication or herbal } \\
\text { injections }\end{array}$ & $4.4 \%$ & $14.9 \%$ & $24.6 \%$ & $30.7 \%$ & $25.4 \%$ & 3.58 & 1.15 \\
\hline Total & & & & & & 3.92 & \\
\hline
\end{tabular}

Table 3 Neutral Effects of DRG Payment Reform on Physicians' Behavior

\begin{tabular}{|c|c|c|c|c|c|c|c|}
\hline & $\begin{array}{l}\text { Strongly } \\
\text { Disagree }\end{array}$ & Disagree & Neutral & Agree & $\begin{array}{l}\text { Strongly } \\
\text { Agree }\end{array}$ & Mean & SD \\
\hline More pre-admission examinations & $1.8 \%$ & $3.5 \%$ & $18.4 \%$ & $34.2 \%$ & $42.1 \%$ & 4.11 & 0.95 \\
\hline $\begin{array}{l}\text { Replace higher-priced originals with lower-priced } \\
\text { generics }\end{array}$ & $7.9 \%$ & $14.0 \%$ & $21.9 \%$ & $38.6 \%$ & $17.5 \%$ & 3.44 & 1.17 \\
\hline Increase patient referrals & $6.1 \%$ & $14.0 \%$ & $33.3 \%$ & $37.7 \%$ & $8.8 \%$ & 3.29 & 1.02 \\
\hline Total & & & & & & 3.61 & \\
\hline
\end{tabular}

between the hospitals' policy implementation group and the non-implementation group. Table 5 shows the only scores that had a statistically significant difference between the two groups. The obtained results indicated that many hospitals' policies impacted the physicians' behavior, with both an increased score and a decreased score. Among all mentioned hospitals' policies, "promote clinical pathway implementation" had the greatest influence on the physicians' behaviors. In total, seven physician behaviors changed including reducing examination after admission, the time of medications prescribed, adjuvant medications and prophylactic antibiotics, replacing higher-priced originals with lower-priced generics, and preventing more pre-admission examinations and case splitting. Despite the broad and favorable impact of "promote clinical pathway implementation", it was not the most implemented policy according to the results shown in Figure 2. There was only $61.4 \%$ of respondents acknowledged that their hospital implemented the policy. The next most influential hospitals' policy was "limit the 
Table 4 Negative Effects of DRG Payment Reform on Physicians' Behavior

\begin{tabular}{|c|c|c|c|c|c|c|c|}
\hline & $\begin{array}{l}\text { Strongly } \\
\text { Disagree }\end{array}$ & Disagree & Neutral & Agree & $\begin{array}{l}\text { Strongly } \\
\text { Agree }\end{array}$ & Mean & SD \\
\hline Increase explanation to the patients & $0.9 \%$ & $6.1 \%$ & $19.3 \%$ & $36.0 \%$ & $37.7 \%$ & 4.04 & 0.95 \\
\hline Reduce expensive new sophisticated technology & $3.5 \%$ & $11.4 \%$ & $26.3 \%$ & $34.2 \%$ & $24.6 \%$ & 3.65 & 1.08 \\
\hline Case split & $4.4 \%$ & $14.9 \%$ & $29.8 \%$ & $35.1 \%$ & $15.8 \%$ & 3.43 & 1.06 \\
\hline Select the more profitable cases & $3.5 \%$ & $19.3 \%$ & $24.6 \%$ & $37.7 \%$ & $14.9 \%$ & 3.41 & 1.07 \\
\hline $\begin{array}{l}\text { Accept more patients without medical insurance or } \\
\text { non-local }\end{array}$ & $1.8 \%$ & $17.5 \%$ & $34.2 \%$ & $37.7 \%$ & $8.8 \%$ & 3.34 & 0.93 \\
\hline Cost shift to outpatient & $5.3 \%$ & $26.3 \%$ & $26.3 \%$ & $31.6 \%$ & $10.5 \%$ & 3.16 & 1.09 \\
\hline Increase volumes of admissions & $10.5 \%$ & $23.7 \%$ & $17.5 \%$ & $39.5 \%$ & $8.8 \%$ & 3.12 & 1.18 \\
\hline Upcode & $16.7 \%$ & $18.4 \%$ & $20.2 \%$ & $33.3 \%$ & $11.4 \%$ & 3.04 & 1.29 \\
\hline Increase the use of out-of-pocket medications & $16.7 \%$ & $25.4 \%$ & $27.2 \%$ & $18.4 \%$ & $12.3 \%$ & 2.84 & 1.26 \\
\hline Refuse to admit critically ill patients & $14.0 \%$ & $36.0 \%$ & $17.5 \%$ & $18.4 \%$ & $14.0 \%$ & 2.82 & 1.29 \\
\hline Premature discharges & $19.3 \%$ & $26.3 \%$ & $22.8 \%$ & $20.2 \%$ & $11.4 \%$ & 2.78 & 1.29 \\
\hline Deny care to cases with over the ceiling prices & $24.6 \%$ & $26.3 \%$ & $12.3 \%$ & $25.4 \%$ & $11.4 \%$ & 2.73 & 1.38 \\
\hline Total & & & & & & 3.20 & \\
\hline
\end{tabular}

proportional cost of total medical expenses", with a total of six physicians' behaviors changed. In the policy implementation group, three physicians' behaviors were added including "reduce the number of medications prescribed", "replace higher-priced originals with lower-priced generics", and "reduce the use of expensive consumables". The other three behaviors reduced which included "more preadmission examinations", "accept more patients without medical insurance or non-local", and "case split".

It is worth noting that most of the hospitals' policies promoted the positive effect and prevented the negative effect under DRG payment. However, some notable hospitals' policies amplified the negative effects. Hospitals that have adopted the "limit hospitalization costs" policy were more inclined to refuse admission for critically ill patients and deny care to patients whose conditions could lead to significant costs above the ceiling prices. Similarly, the "limit the length of stay" policy also intensified the increase in pre-admission examinations and denied care to cases that could lead to over the ceiling prices.

The network analysis was constructed to visualize the association between hospitals' policy and physicians' behavior (Figure 3), based on the results shown in Table 4. There were 32 nodes (11 yellow nodes which represented hospitals' policy and 21 blue nodes which represented physicians' behavior) and 43 edges in the obtained network analysis model. Among the hospitals' policies, we found that nodes B were bigger since they had more edges in the network. And the edge number of the node was 7. In other words, the hospitals' policy could change the corresponding number of physicians' behaviors. Among the physicians' behaviors, nodes 7 and 10 were bigger and had the 6 and 5 edges, respectively, which suggested that they were more susceptible to the hospitals' policies. In addition, Table 4 shows the physicians' behaviors which were increased or decreased under the influence of hospitals' policy.

\section{Discussion}

To the best of our knowledge, this is the first comprehensive study which has examined the impact of DRGs on the healthcare providers' behavior from the physicians' perspective. Our results identified that many hospitals' policies were implemented in response to the DRG payment reform. As a result, the DRG payment system could reduce overtreatment and improve efficiency. However, it also led to negative effects including an increased explanation to the patients, hindering new technologies, case splitting, and cherry picking. Nevertheless, the results indicated that there was no evidence of serious negative 
Table 5 Relationship Between Hospitals' Policy and Physicians' Behavior

\begin{tabular}{|c|c|c|c|c|}
\hline Hospitals' Policy & Physicians' Behavior & $\begin{array}{c}\text { Non- } \\
\text { Implementation } \\
(\text { Mean士SD) }\end{array}$ & $\begin{array}{l}\text { Implementation } \\
\text { (Trend) (Mean } \pm \text { SD) }\end{array}$ & $P$ value \\
\hline \multirow[t]{4}{*}{$\begin{array}{l}\text { Strengthen the quality management of the first page on medical } \\
\text { record }\end{array}$} & $\begin{array}{l}\text { Reduce the examination after } \\
\text { admission }\end{array}$ & $3.52 \pm 1.10$ & $3.90 \pm 0.88(\uparrow)$ & 0.044 \\
\hline & $\begin{array}{l}\text { Reduce the time of medications } \\
\text { prescribed }\end{array}$ & $3.56 \pm 0.92$ & $4.00 \pm 0.92(\uparrow)$ & 0.012 \\
\hline & $\begin{array}{l}\text { Replace higher-priced originals with } \\
\text { lower-priced generics }\end{array}$ & $3.19 \pm 1.24$ & $3.65 \pm 1.07(\uparrow)$ & 0.039 \\
\hline & Increase patient referrals & $3.52 \pm 1.00$ & $3.10 \pm 1.00(\downarrow)$ & 0.027 \\
\hline \multirow[t]{7}{*}{ Promote clinical pathway implementation } & More pre-admission examinations & $4.39 \pm 0.92$ & $3.94 \pm 0.93(\downarrow)$ & 0.014 \\
\hline & $\begin{array}{l}\text { Reduce the examination after } \\
\text { admission }\end{array}$ & $3.43 \pm 1.13$ & $3.91 \pm 0.86(\uparrow)$ & 0.018 \\
\hline & $\begin{array}{l}\text { Reduce the time of medications } \\
\text { prescribed }\end{array}$ & $3.57 \pm 0.87$ & $3.94 \pm 0.96(\uparrow)$ & 0.038 \\
\hline & $\begin{array}{l}\text { Reduce the use of adjuvant } \\
\text { medications }\end{array}$ & $3.68 \pm 0.98$ & $4.04 \pm 0.89(\uparrow)$ & 0.045 \\
\hline & $\begin{array}{l}\text { Reduce the use of prophylactic } \\
\text { antibiotics }\end{array}$ & $3.75 \pm 1.04$ & $4.16 \pm 0.74(\uparrow)$ & 0.026 \\
\hline & $\begin{array}{l}\text { Replace higher-priced originals with } \\
\text { lower-priced generics }\end{array}$ & $3.02 \pm 1.27$ & $3.70 \pm 1.03(\uparrow)$ & 0.004 \\
\hline & Case split & $3.68 \pm 1.14$ & $3.27 \pm 0.99(\downarrow)$ & 0.044 \\
\hline \multirow[t]{2}{*}{ Enhance cost accounting management } & $\begin{array}{l}\text { Reduce the time of medications } \\
\text { prescribed }\end{array}$ & $3.54 \pm 0.90$ & $3.98 \pm 0.94(\uparrow)$ & 0.013 \\
\hline & $\begin{array}{l}\text { Increase performance of day } \\
\text { surgery }\end{array}$ & $3.7 I \pm 0.87$ & $4.11 \pm 0.81(\uparrow)$ & 0.014 \\
\hline \multirow[t]{2}{*}{ Transform hospital information system for DRG } & $\begin{array}{l}\text { Reduce the number of medications } \\
\text { prescribed }\end{array}$ & $3.55 \pm 1.02$ & $4.03 \pm 0.84(\uparrow)$ & 0.012 \\
\hline & $\begin{array}{l}\text { Reduce the time of medications } \\
\text { prescribed }\end{array}$ & $3.55 \pm 0.83$ & $3.94 \pm 0.98(\uparrow)$ & 0.029 \\
\hline \multirow[t]{5}{*}{ Carry out the publicity and training of DRG-related knowledge } & $\begin{array}{l}\text { Reduce the number of medications } \\
\text { prescribed }\end{array}$ & $3.65 \pm 0.89$ & $4.02 \pm 0.94(\uparrow)$ & 0.035 \\
\hline & $\begin{array}{l}\text { Reduce the use of prophylactic } \\
\text { antibiotics }\end{array}$ & $3.80 \pm 0.85$ & $4.16 \pm 0.88(\uparrow)$ & 0.032 \\
\hline & Cost-shifting to outpatient & $3.41 \pm 1.04$ & $2.95 \pm 1.10(\downarrow)$ & 0.025 \\
\hline & Refuse to admit critically ill patients & $3.20 \pm 1.20$ & $2.52 \pm 1.28(\downarrow)$ & 0.005 \\
\hline & Increase patient referrals & $3.53 \pm 0.73$ & $3.10 \pm 1.17(\downarrow)$ & 0.017 \\
\hline \multirow[t]{4}{*}{$\begin{array}{l}\text { Include DRG relevant indicators in the performance appraisal } \\
\text { system of a department or physician }\end{array}$} & $\begin{array}{l}\text { Strict control of the surgical } \\
\text { indication }\end{array}$ & $4.07 \pm 0.80$ & $4.38 \pm 0.74(\uparrow)$ & 0.047 \\
\hline & $\begin{array}{l}\text { Reduce the time of medications } \\
\text { prescribed }\end{array}$ & $3.40 \pm 0.98$ & $4.01 \pm 0.85(\uparrow)$ & 0.001 \\
\hline & $\begin{array}{l}\text { Accept more patients without } \\
\text { medical insurance or non-local }\end{array}$ & $3.58 \pm 1.04$ & $3.22 \pm 0.85(\downarrow)$ & 0.049 \\
\hline & Select the more profitable cases & $3.70 \pm 0.94$ & $3.26 \pm 1.11(\downarrow)$ & 0.034 \\
\hline
\end{tabular}

(Continued) 
Table 5 (Continued).

\begin{tabular}{|c|c|c|c|c|}
\hline Hospitals' Policy & Physicians' Behavior & $\begin{array}{c}\text { Non- } \\
\text { Implementation } \\
(\text { Mean } \pm S D)\end{array}$ & $\begin{array}{l}\text { Implementation } \\
\text { (Trend) (Mean士SD) }\end{array}$ & $P$ value \\
\hline \multirow[t]{2}{*}{$\begin{array}{l}\text { Summarize the operation of DRG and give regular feedback to } \\
\text { the department or physician }\end{array}$} & $\begin{array}{l}\text { More compliance with clinical } \\
\text { pathway }\end{array}$ & $3.90 \pm 0.50$ & $4.18 \pm 0.45(\uparrow)$ & 0.003 \\
\hline & $\begin{array}{l}\text { Increase the use of essential } \\
\text { medications }\end{array}$ & $3.70 \pm 0.97$ & $4.05 \pm 0.86(\uparrow)$ & 0.047 \\
\hline \multirow[t]{5}{*}{ Limit the usage of expensive medications or consumables } & Shorten the length of stay & $3.52 \pm 1.03$ & $3.95 \pm 0.72(\uparrow)$ & 0.011 \\
\hline & $\begin{array}{l}\text { Reduce the time of medications } \\
\text { prescribed }\end{array}$ & $3.55 \pm 0.94$ & $4.05 \pm 0.88(\uparrow)$ & 0.004 \\
\hline & $\begin{array}{l}\text { Reduce the use of adjuvant } \\
\text { medications }\end{array}$ & $3.69 \pm 1.06$ & $4.13 \pm 0.74(\uparrow)$ & 0.012 \\
\hline & Increase volumes of admissions & $3.34 \pm 1.02$ & $2.89 \pm 1.30(\downarrow)$ & 0.042 \\
\hline & Case split & $3.71 \pm 1.06$ & $3.14 \pm 1.00(\downarrow)$ & 0.004 \\
\hline \multirow{6}{*}{$\begin{array}{l}\text { Limit the proportional cost of total medical expenses (eg the } \\
\text { proportion of medication or consumable costs) }\end{array}$} & More pre-admission examinations & $4.3 I \pm 0.75$ & $3.93 \pm 1.07(\downarrow)$ & 0.031 \\
\hline & $\begin{array}{l}\text { Reduce the number of medications } \\
\text { prescribed }\end{array}$ & $3.65 \pm 0.94$ & $4.03 \pm 0.90(\uparrow)$ & 0.027 \\
\hline & $\begin{array}{l}\text { Replace higher-priced originals with } \\
\text { lower-priced generics }\end{array}$ & $3.17 \pm 1.16$ & $3.68 \pm 1.13(\uparrow)$ & 0.018 \\
\hline & $\begin{array}{l}\text { Reduce the use of expensive } \\
\text { consumables }\end{array}$ & $3.85 \pm 1.04$ & $4.23 \pm 0.81(\uparrow)$ & 0.030 \\
\hline & $\begin{array}{l}\text { Accept more patients without } \\
\text { medical insurance or non-local }\end{array}$ & $3.56 \pm 0.86$ & $3.15 \pm 0.95(\downarrow)$ & 0.019 \\
\hline & Case split & $3.74 \pm 0.89$ & $3.15 \pm 1.13(\downarrow)$ & 0.003 \\
\hline \multirow[t]{3}{*}{ Limit hospitalization costs } & $\begin{array}{l}\text { Replace higher-priced originals with } \\
\text { lower-priced generics }\end{array}$ & $3.29 \pm 1.15$ & $3.89 \pm 1.13(\uparrow)$ & 0.017 \\
\hline & Refuse to admit critically ill patients & $2.64 \pm 1.19$ & $3.39 \pm 1.42(\uparrow)$ & 0.015 \\
\hline & $\begin{array}{l}\text { Deny care to cases with over the } \\
\text { ceiling prices }\end{array}$ & $2.53 \pm 1.32$ & $3.32 \pm 1.42(\uparrow)$ & 0.008 \\
\hline \multirow[t]{3}{*}{ Limit the length of stay } & More pre-admission examinations & $3.58 \pm 1.10$ & $4.26 \pm 0.86(\uparrow)$ & 0.002 \\
\hline & $\begin{array}{l}\text { Replace higher-priced originals with } \\
\text { lower-priced generics }\end{array}$ & $3.30 \pm 1.14$ & $3.96 \pm 1.16(\uparrow)$ & 0.013 \\
\hline & $\begin{array}{l}\text { Deny care to cases with over the } \\
\text { ceiling prices }\end{array}$ & $2.59 \pm 1.34$ & $3.25 \pm 1.42(\uparrow)$ & 0.036 \\
\hline
\end{tabular}

Notes: $\uparrow$ Meaning the score increased in the hospitals where the policy was implemented compared with those not implemented; $\downarrow$ Meaning the score decreased in the hospitals where the policy was implemented compared with those not implemented.

effects such as refusing patient and premature discharge. Overall, the benefits outweighed the drawbacks. Moreover, the hospitals' policies could significantly change several physician behaviors. Promoting the implementation of clinical pathways had the most positive impact, while limiting costs and LOS were not recommended. Therefore, our findings have important implications for researchers and policymakers in many LMICs which are introducing or reforming the DRG payment systems.

Although hospital management was more knowledgeable about hospital policy, there was an important part of this study that explored the relationship between hospital policy and physician behavior, and it was more convenient and reliable to examine the relevance of involving hospital 


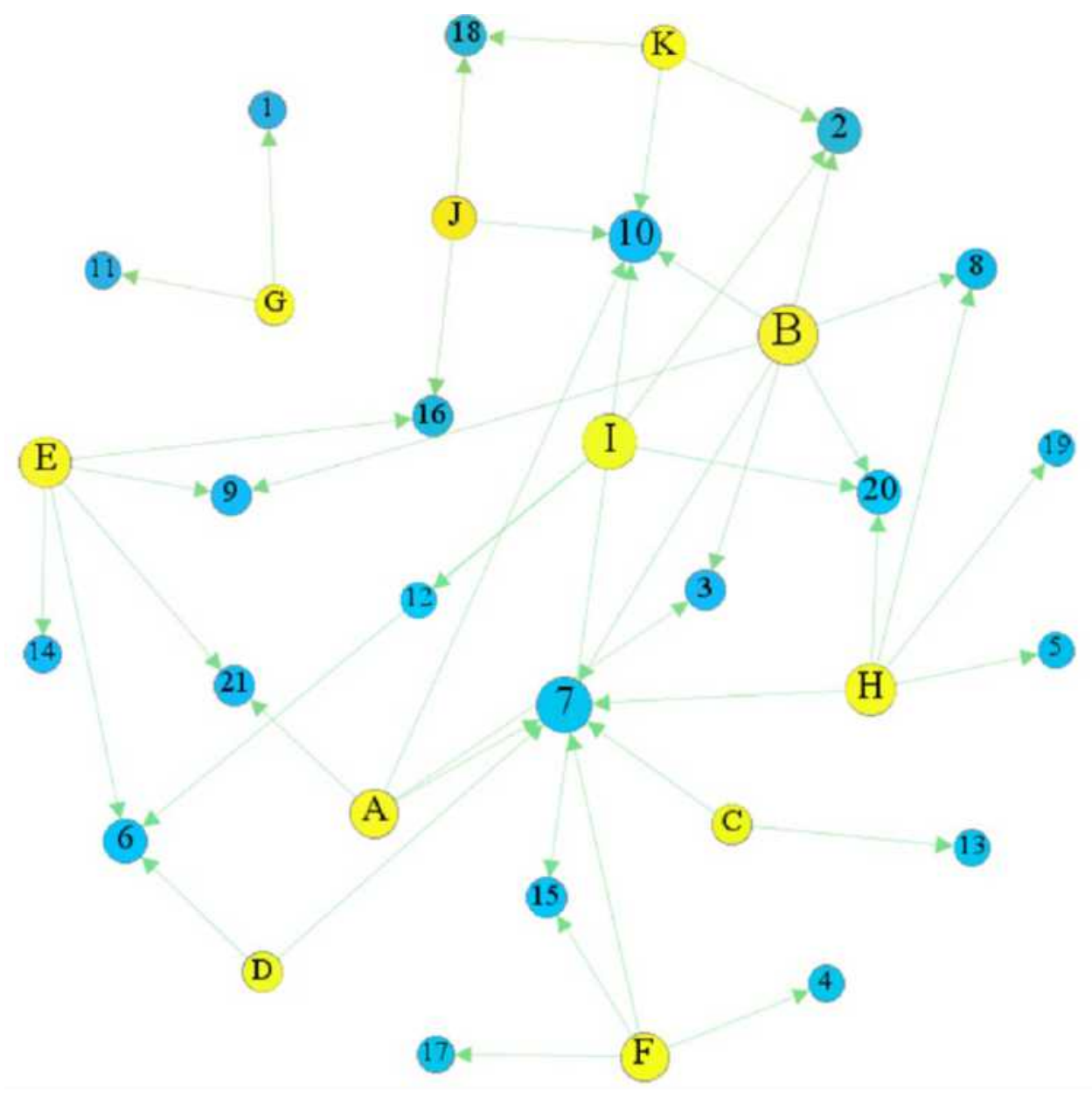

Figure 3 The network model linking hospitals' policy and physicians' behavior.

Notes: Yellow nodes represent the hospitals' policies, while the blue nodes represent the physicians' behavior. Node labels' interpretation: A. Strengthen the quality management of the first page on medical record; B. Promote clinical pathway implementation; C. Enhance cost accounting management; D. Transform hospital information system for DRG; E. Carry out the publicity and training of DRG-related knowledge; F. Include DRG relevant indicators in the performance appraisal system of a department or physician; G. Summarize the operation of DRG and give regular feedback to the department or physician; $\mathrm{H}$. Limit the usage of expensive medications or consumables; I. Limit the proportional cost of total medical expenses (eg the proportion of medication or consumable costs); J. Limit hospitalization costs; K. Limit the length of stay; I. More compliance with clinical pathway; 2 . More pre-admission examinations; 3 . Reduce the examination after admission; 4 . Strict control of the surgical indication; 5. Shorten the length of stay; 6 . Reduce the number of medications prescribed; 7. Reduce the time of medications prescribed; 8 . Reduce the use of adjuvant medications; 9. Reduce the use of prophylactic antibiotics; 10. Replace higher-priced originals with lower-priced generics; II. Increase the use of essential medications; I2. Reduce the use of expensive consumables; 13. Increase the performance of day surgery; 14. Cost-shift to outpatient; 15. Accept more patients without medical insurance or non-local; 16. Refuse to admit critically ill patients; 17. Select the more profitable cases; 18. Deny care to cases with over the ceiling prices; 19. Increase volumes of admissions; 20. Case split; and 21 . Increase patient referrals.

policy and physician behavior in the same questionnaire and completed by one respondent. Besides, hospital policies were implemented by physicians, and they were familiar with them. Therefore, instead of seeking the response for hospital policy from the hospital management and physician behavior from physician respectively, we selected physician as the survey respondent. 80 out of the selected 200 physicians were excluded because they were not familiar with DRG. Even in the DRG pilot cities, there were still many physicians who did not know about it. Thus, there is a need to increase the publicity in order to promote the DRG payment reform. Grade-A tertiary hospitals are the highest-level hospitals in China's medical delivery system. Therefore, they are more likely to be equipped with sophisticated accounting systems and health information systems, which are necessary for DRG payment. This led to more Grade-A tertiary hospitals being chosen as the DRG payment pilot hospitals than secondary and primary hospitals. That might be the reason why more than one-third of the respondents were from Grade-A tertiary hospitals since familiarity with DRG was a requirement for inclusion in this study. The two most common policies adopted by the hospitals indicated that hospital administrators were fully aware of the importance 
of physician involvement in the reform. However, doctors in South Korea complained that they were excluded from the implementation of DRG. ${ }^{22}$

Our results revealed that the main positive effects of DRG were to improve efficiency and curb unnecessary healthcare. The physicians admitted that they would have stricter control of the surgical indications under the DRG payment system. Similar results were also reported in previous studies which found that the DRG payment was associated with a low likelihood of cesarean sections. ${ }^{23,24}$ In addition, the treatment process was optimized and the waiting time was reduced, which was consistent with the observation of Waitzberg et al. ${ }^{25}$ Introduction of the DRGs led to a decrease in the use of expensive consumables, which was supported by results reported in an empirical study in obstetrics and gynecology conducted in South Korea. $^{26}$ Furthermore, the reduction in LOS and care intensity was defined as a positive effect because overtreatment was universal in the previously used FFS system. However, a previous study reported that the reduction of excessive care intensity can compromise care quality and patient interest. ${ }^{3}$ Therefore, we should establish and enact mechanisms to monitor and assure the healthcare quality in order to prevent hospitals from sacrificing healthcare quality to control cost.

A neutral effect meant that it was difficult to determine whether the DRG payment led to a positive or negative effect. For example, the occurrence of more pre-admission examinations might be to obtain a more accurate diagnosis for the correct grouping, or shift costs to outpatient thereby reducing examinations after admission. Moreover, replacing higher-priced originals with lower-priced generics could save cost, but the quality of generics must be assured, which was doubtful according to Chinese physicians. $^{27}$ Increasing patient referrals might imply more coordination among hospitals and mature hierarchical medical schemes, but it might also imply refusing specific patients or inappropriate early discharge.

This study found that the main negative effect brought by the DRG payment system was increasing explanation to the patients. In the early adoption of DRG, it was challenging for the patients to understand DRG because they were accustomed to the traditional FFS payment system. Therefore, physicians should include explanations at the early stages of reform so that patients can fully understand the advantages of DRG and prevent deterioration of the physician-patient relationship. Besides, a study conducted under the Swiss-DRG system reported that the patients felt more insecure, had more problems with self-care, and felt more pain or discomfort. ${ }^{28}$ This might be another reason why the physicians increased explanation to the patients. The other negative effect of the DRG payment system was reducing the use of expensive new sophisticated technology, which was consistent with a previous theoretical literature. $^{29}$ The potential solutions were paying hospitals for the extra costs of the new technology in the short term and adjusting the DRG tariff in the long term. The physicians also identified other apparent negative effects including case splitting and cherry picking. Upcoding, another primary concern under DRG payment, refers to hospitals increasing their reimbursement by coding additional diagnoses in order to move patients into higher-paying groups. Studies conducted in the USA and German reported that hospitals upcoded their patients with the goal of receiving additional payments. ${ }^{30,31}$ Another study conducted in Israel found more precision in coding procedures and diagnosis, but did not find upcoding. ${ }^{25}$ However, this study found that the physicians held different views on whether it existed and no clear bias had been observed.

Unlike the findings reported in a previous study, ${ }^{1}$ the worries about refusing or denying care to specific patients and premature discharges were not evident in this study. This indicates that the pursuit of economic profits by healthcare providers was not too excessive to an extent of refusing or denying care to patients and premature discharges. Therefore, the situation was not worse despite the financial pressure. This can be attributed to the fact that the payers reimburse hospitals rather than physicians, and thus the physicians were insensitive to such indirect incentives. Another explanation might be that collectivistic values and professional ethics are strongly emphasized in China. $^{32}$ Thus, in this cultural context, the physicians would prioritize the quality of care and patient safety over economic incentives. However, follow-up studies are required to verify whether the unintended effects exist in the long run.

We recommend that hospitals should promote clinical pathways based on our analysis of the association between hospitals' policy and physicians' behavior. Similarly, Yip et al also suggested that adherence to the clinical pathway is a viable option for ensuring that providers do not compromise the quality of care. ${ }^{33}$ This study indicated that the situation would become worse if hospitals limited the hospitalization costs and LOS. In addition, previous studies have reported that such cost-control actions limited the physicians' performance and decreased patient 
satisfaction. ${ }^{27}$ Fortunately, these two policies were the least implemented among all hospitals' policies. Additionally, we included 29 physicians' behaviors in this analysis. The obtained results indicated that 21 behaviors were associated with the hospitals' policies, while the remaining eight behaviors were not associated with the implementation of hospitals' policies. These results suggested the complexity of physicians' behavior, which cannot always directly react to hospitals' policies. Moreover, the commitment to the patients and preferences, ethical considerations, and clinical considerations could all affect clinical practice. $^{25}$

There is a need to assess whether healthcare quality and equality are compromised and whether medical ethics are eroded after every reform of a hospital reimbursement system. Therefore, a survey of healthcare stakeholders should be an essential part of such assessment as well as conducting rigorous empirical studies using hospital data or patient data. The results obtained after conducting a questionnaire survey among physicians can help identify the physician views on DRG, possible problems during clinical practice, and assess the appropriateness of the hospitals' response, thereby contributing to further development of DRG in China. Although the physicians involved in this study saw more positive effects than negative effects of DRG on their behavior, we are still worried that the quality and equality could be compromised if the hospital put more economic pressure on them such as limiting the cost and LOS on physicians. Moreover, we should pay full attention to the negative effects of DRG including increasing the workload, inhibiting new techniques, case splitting, and taking measures to deal with them.

This study had several limitations and future research directions should be considered. Firstly, the subjective assessments of physicians may not accurately reflect the real situation. Some negative effects may be underestimated because the physicians were unwilling to admit that they did it. Therefore, further empirical studies using real-world data are required in order to verify our findings. Secondly, this study was just conducted at the beginning of the nationwide DRG payment reform. Thus, the progress in each city was different, where some cities had already started DRG implementation while some were still running simulations. Observations at this point in time may be inconsistent with full DRG implementation. Further research is required to observe the mid- and long-term effects of the introduction of DRGs. Thirdly, the small number of participants $(n=114)$ in this study can limit the generalizability of our findings. However, we still believe that our results are representative and reliable because we conducted the survey in five different nationwide cities in China, and the sample characteristics were similar to the overall characteristics. Nonetheless, further studies with larger sample size are still needed in the future.

\section{Conclusion}

Respondents stated that many hospitals' policies were implemented in response to the DRG payment reform. The Chinese physicians who participated in the questionnaire suggested that the DRG payment system led to many changes in their behavior and they possessed relatively positive attitudes towards DRG. The results were reassuring for the continued implementation of the DRG payment reform pilot in China. However, concerns must be raised that improving efficiency should not come at the expense of care quality and equality, and countermeasures should be taken to prevent the negative impact. Meanwhile, the physicians' behavior was associated with hospitals' policies. Therefore, clinical pathways should be implemented more often, and limiting hospitalization costs and LOS should be used with caution. In the future, more studies with real-world data, long-term follow-up and large sample sizes are needed to validate our findings.

\section{Abbreviations}

DRG, diagnosis-related groups; LOS, length of stay; GDP, gross domestic product; FFS, fee-for-service; LMICs, lowand middle-income countries; CVI, content validity index.

\section{Ethics Approval}

The study was approved by the Ethics Committee of Shenyang Pharmaceutical University, and physicians gave their written informed consent before participating in the questionnaires.

\section{Acknowledgments}

The authors would like to thank all the physicians who participated in this study.

\section{Disclosure}

The authors report no conflicts of interest in this work. 


\section{References}

1. Busse R, Geissler A, Aaviksoo A, et al. Diagnosis related groups in Europe: moving towards transparency, efficiency, and quality in hospitals. BMJ. 2013;346:f3197. doi:10.1136/bmj.f3197

2. Mathauer I, Wittenbecher F. Hospital payment systems based on diagnosis-related groups: experiences in low- and middle-income countries. Bull World Health Organ. 2013;91(10):746-756A. doi:10.2471/BLT.12.115931

3. Jian W, Lu M, Liu G, Chan KY, Poon AN. Beijing's diagnosis-related group payment reform pilot: impact on quality of acute myocardial infarction care. Soc Sci Med. 2019;243:112590. doi:10.1016/j. socscimed.2019.112590

4. Ljunggren B, Sjödén PO. Patient-reported quality of life before, compared with after a DRG intervention. Int J Qual Health Care. 2003;15(5):433-440. doi:10.1093/intqhe/mzg066

5. Lin HC, Yang MC, Chen CC, Tang CH. Opinions of hospital administrators toward the prevalence of patient dumping in Taiwan. Chang Gung Med J. 2004;27(1):35-43.

6. National Health Commission. Statistical bulletin on the development of health in China in 2019. Available from: http://www.nhc.gov.cn/ guihuaxxs/s10748/202006/ebfe31f24cc145b198dd730603ec4442. shtml. Accessed August 11, 2020.

7. National Bureau of Statistics of China. China statistical yearbook in 2019. Available from: http://www.stats.gov.cn/tjjj/ndsj/2019/indexch. htm. Accessed August 11, 2020.

8. National Healthcare Security Administration. Healthcare development bulletin in 2019. Available from: http://www.nhsa.gov.cn/art/ 2020/3/30/art_7_2930.html. Accessed August 11, 2020.

9. Yip WC, Hsiao W, Meng Q, Chen W, Sun X. Realignment of incentives for health-care providers in China. Lancet. 2010;375 (9720):1120-1130. doi:10.1016/S0140-6736(10)60063-3

10. The General Office of the State Council. The Guiding opinions on further deepening the reform of basic medical insurance payment methods. Available from: http://www.gov.cn/zhengce/content/201706/28/content_5206315.htm. Accessed August 11, 2020.

11. National Healthcare Security Administration. Notification of national pilot cities for DRG payment. Available from: http://www.nhsa.gov. cn/art/2019/6/5/art_37_1362.html. Accessed August 11, 2020.

12. Kahn KL, Keeler EB, Sherwood MJ, et al. Comparing outcomes of care before and after implementation of the DRG-based prospective payment system. JAMA. 1990;264(15):1984-1988. doi:10.1001/ jama.1990.03450150084036

13. Kwon S. Payment system reform for health care providers in Korea. Health Policy Plan. 2003;18(1):84-92. doi:10.1093/heapol/18.1.84

14. Hamada H, Sekimoto M, Imanaka Y. Effects of the per diem prospective payment system with DRG-like grouping system (DPC/ PDPS) on resource usage and healthcare quality in Japan. Health Policy. 2012;107(2-3):194-201. doi:10.1016/j.healthpol.2012.01.002

15. Hu WY, Yeh CF, Shiao AS, Tu TY. Effects of diagnosis-related group payment on health-care provider behaviors: a consecutive three-period study. J Chin Med Assoc. 2015;78(11):678-685. doi:10.1016/j.jcma.2015.06.012

16. Zou K, Li HY, Zhou D, Liao ZJ. The effects of diagnosis-related groups payment on hospital healthcare in China: a systematic review. BMC Health Serv Res. 2020;20(1):112. doi:10.1186/s12913-0204957-5

17. Zhao C, Wang C, Shen C, Wang Q. Diagnosis-related group (DRG)-based case-mix funding system, a promising alternative for fee for service payment in China. Biosci Trends. 2018;12(2):109-115. doi:10.5582/bst.2017.01289
18. Zhang YH, He GP, Liu JW. Comparison of medical costs and care of appendectomy patients between fee-for-service and set fee for diagnosis-related group systems in 20 Chinese hospitals. Southeast Asian J Trop Med Public Health. 2016;47(5):1055-1061.

19. Zhang J. The impact of a diagnosis-related group-based prospective payment experiment: the experience of Shanghai. Appl Econ Lett. 2010;17(18):1797-1803. doi:10.1080/13504850903317347

20. Faul F, Erdfelder E, Lang AG, Buchner A. G*Power 3: a flexible statistical power analysis program for the social, behavioral, and biomedical sciences. Behav Res Methods. 2007;39(2):175-191. doi:10.3758/BF03193146

21. Sullivan GM, Artino AR Jr. Analyzing and interpreting data from likert-type scales. $J$ Grad Med Educ. 2013;5(4):541-542. doi:10.4300/JGME-5-4-18

22. Shon C, You M. Evaluation of health policy governance in the introduction of the new DRG-based hospital payment system from interviews with policy elites in South Korea. Int J Environ Res Public Health. 2020;17(11):3757. doi:10.3390/ijerph17113757

23. Kim SJ, Han KT, Kim SJ, Park EC, Park HK. Impact of a diagnosis-related group payment system on cesarean section in Korea. Health Policy. 2016;120(6):596-603. doi:10.1016/j. healthpol.2016.04.018

24. Yu Y, Lin F, Dong W, Li H, Zhang X, Chen C. The effectiveness of financial intervention strategies for reducing caesarean section rates: a systematic review. BMC Public Health. 2019;19(1):1080. doi:10.1186/s12889-019-7265-4

25. Waitzberg R, Quentin W, Daniels E, Pald Y, Busse R, Greenberg D. Effects of activity-based hospital payments in Israel: a qualitative evaluation focusing on the perspectives of hospital managers and physicians [published online ahead of print]. Int $J$ Health Policy Manag. 2020. doi:10.34172/ijhpm.2020.51

26. Jung YW, Pak H, Lee I, Kim EH. The effect of diagnosis-related group payment system on quality of care in the field of obstetrics and gynecology among Korean Tertiary Hospitals. Yonsei Med J. 2018;59 (4):539-545. doi:10.3349/ymj.2018.59.4.539

27. Yan J, Lin HH, Zhao D, Hu Y, Shao R. China's new policy for healthcare cost-control based on global budget: a survey of 110 clinicians in hospitals. BMC Health Serv Res. 2019;19(1):84. doi:10.1186/s12913-019-3921-8

28. Thommen D, Weissenberger N, Schuetz P, et al. Head-to-head comparison of length of stay, patients' outcome and satisfaction in Switzerland before and after SwissDRG-Implementation in 2012: an observational study in two tertiary university centers. Swiss Med Wkly. 2014;144:w13972. doi:10.4414/smw.2014.13972

29. Stern RS, Epstein AM. Institutional responses to prospective payment based on diagnosis-related groups. Implications for cost, quality, and access. $N$ Engl J Med. 1985;312(10):621-627. doi:10.1056/ NEJM198503073121005

30. Steinwald B, Dummit LA. Hospital case-mix change: sicker patients or DRG creep. Health Aff (Millwood). 1989;8(2):35-47. doi:10.1377/ hlthaff.8.2.35

31. Jürges H, Köberlein J. What explains DRG upcoding in neonatology? The roles of financial incentives and infant health. $J$ Health Econ. 2015;43:13-26. doi:10.1016/j.jhealeco.2015.06.001

32. Jin P, Biller-Andorno N, Wild V. Ethical implications of case-based payment in China: a systematic analysis. Dev World Bioeth. 2015;15 (3):134-142. doi:10.1111/dewb.12055

33. Yip WC, Hsiao WC, Chen W, Hu S, Ma J, Maynard A. Early appraisal of China's huge and complex health-care reforms. Lancet. 2012;379(9818):833-842. doi:10.1016/S0140-6736(11) 61880-1 


\section{Publish your work in this journal}

Risk Management and Healthcare Policy is an international, peerreviewed, open access journal focusing on all aspects of public health, policy, and preventative measures to promote good health and improve morbidity and mortality in the population. The journal welcomes submitted papers covering original research, basic science, clinical \& epidemiological studies, reviews and evaluations, guidelines, expert opinion and commentary, case reports and extended reports. The manuscript management system is completely online and includes a very quick and fair peer-review system, which is all easy to use. Visit http://www.dovepress.com/testimonials.php to read real quotes from published authors. 